\title{
Baikal Region: Urbanization and Industrialization
}

DOI: 10.31551/2410-2725-2018-4-2-265-275

\section{Baldano Marina Namzhilovna}

Doctor of Historical Sciences, Professor, Chief researcher, Coordinator of the Department of history, Ethnology and sociology, The Institute for Mongolian, Buddhist and Tibetan Studies of the Siberian Branch of the Russian Academy of Sciences. Russian Federation, 670047, Ulan-Ude, ul. Sakhyanova, 6. E-mail: histmar@mail.ru

Abstract. The article deals with the problem of urban development in the process of industrialization, complicated by the need to overcome the huge difficulties associated with the peculiarities of the economy and culture of the Baikal region. The nature of urbanization development as a consequence of forced industrialization is analyzed, the existing gap between these processes, the uneven industrial development and the formation of the urban system in the region are shown in the article.

Key words: Baikal region; Buryatia; Irkutsk region; urbanization; industrialization; city; urban settlements; citizens.

\section{Байкал аймағы: урбанизация және индустриализация}

\section{Балдано Марина Намжиловна}

тарих ғылымдарының докторы, профессор, РҒА Сібір бөлімінің моңғолтану, буддология және тибетология Институтының тарих, этнология және әлеуметтану бөлімінің координаторы, бас ғылыми қызметкер. Ресей Федерациясы, 670047, Улан-Удэ қ, Сахьянова к, 6. E-mail: histmar@mail.ru

Аңдатпа. Мақалада Байкал аймағының ерекшелігін есепке ала отырып шешуге тиісті мәселелер аясындағы индустрияландыру үрдісіндегі қалалардың даму мәселелері қарастырылған. Индустрияландырудың жеделдетілуінің салдары әсер еткен урбанизацияның даму қарқыны талданады, осы үдерістер арасындағы алшақтық, индустриялық дамудың біркелкі емес болуы және аймақтағы қалалық жүйенің қалыптасуы көрсетіледі.

Кілт сөздер: Байкал аймағы; Бурятия; Иркутск облысы; урбанизация; индустриализация;қала; қала қоныстары; азаматтар.

\section{Байкальский регион: урбанизация и индустриализация}

\section{Балдано Марина Намжиловна}

доктор исторических наук, профессор, главный научный сотрудник, координатор отдела истории, этнологии и социологии Института монголоведения, буддологии и тибетологии Сибирского отделения РАН. Российская Федерация, 670047, г. Улан-Удэ, ул. Сахьяновой, 6. E-mail: histmar@mail.ru

Аннотация. В статье рассмотрена проблема развития городов в процессе индустриализации, осложненной необходимостью преодолевать громадные трудности, связанные с особенностями развития экономики и культуры Байкальского региона. Проанализирован характер развития урбанизации как следствия форсированной индустриализации, показаны существующий разрыв между этими процессами, неравномерность промышленного развития и формирования городской системы в регионе. Ключевые слова: Байкальский регион; Бурятия; Иркутская область; урбанизация; индустриализация; город; городские поселения; горожане. 


\title{
әОЖ/ УДК 94+325.111(292.516)
}

\section{Байкальский регион: урбанизация и индустриализация'}

\author{
М.Н. Балдано
}

Проблема города как предмет научного изучения не нова, она находилась в поле зрения исследователей ряда научных дисциплин, так или иначе связанных с изучением городской феноменологии, и относительно долго исследовалась наряду с другими процессами и явлениями, которым посвящались общие комплексные труды по истории, экономике, культуре, архитектуре и т.д. В зарубежной и отечественной научной урбанистической мысли утвердилось и доминировало представление, что город был и в древности, и во все последующие эпохи, а урбанизации не было. Появление и развитие урбанизации связывалось в основном с радикальными изменениями в обществе - в экономике, социуме и общественном сознании, начало которым было положено мануфактурой и промышленной стадией развития.

Придерживаясь данного тезиса, попытаемся хотя бы схематично рассмотреть проблему развития городов в Байкальском регионе (куда мы включили Республику Бурятия и Иркутскую область) в процессе индустриализации, осложненной необходимостью преодолевать громадные трудности, связанные с особенностями развития экономики и культуры региона. Как известно, урбанизация в России стала важнейшим рычагом модернизации общества. Незавершенный, переходный характер советского варианта модернизации все чаще рассматривается как его важнейшая черта. Выйдя за рамки традиционного, российское общество не стало и вполне современным; переход от аграрной экономики к индустриальной сопровождался ее милитаризацией; периоды реформирования сменяли годы застоя, консолидации - расколом общества и т.д. (Пивоваров 2010: 231). Такой же незавершенный, переходный характер был присущ и советской модели урбанизации, сложившейся в основном в 19301980-е гг. Суть этой модели - радикальные изменения при сохранении многих основополагающих звеньев традиционалистского социального устройства.

Незавершенный характер развития урбанизации явился следствием фрорсированной индустриализации, имевшей свои специфические черты: в целях достижение экономической независимости, превращение СССР из «страны, ввозящей машины, в страну, их производящую»; в методах - упор на развитие группы отраслей тяжелой промышленности, обеспечение развития промышленности на основе пятилетних планов; в сроках и темпах осуществления стремительный промышленный рост, высочайшие темпы довоенных пятилеток; в цене - высокие темпы обеспечивались за счет перекачки средств из аграрного сектора в промышленный. Само индустриальное развитие осуществлялось на основе государственного сектора с планово-централизованными механизмами экономики, общественной собственностью, при помощи методов внеэкономического (в том числе и идеологического) принуждения, стимулировавшего народные массы на трудовые достижения.

Значение и скорость этих процессов были действительно впечатляющими: всего за 13 лет, с 1929 по 1940 гг., был сделан существенный прорыв в эконо-

\footnotetext{
${ }^{1}$ Работа выполнена в рамках государственного задания Федерального государственного бюджетного учреждения науки «Институт монголоведения, буддологии и тибетологии Сибирского отделения Российской академии наук (ИМБТ СО РАН)» по проекту XII.191.1.1. «Трансграничье России, Монголии и Китая: история, культура, современное общество», номер госрегистрации № АAАА-А17-117021310269-9.
} 
мическом развитии и создании громадной военно-индустриальной, интеллектуальной, научно-технической и технологической структуры. Вместе с тем, форсированная индустриализация нарушила естественно-историческую эволюцию низших форм промышленного производства, из-за чего изменились последовательность и сменяемость его фраз - от ручного труда к машинной индустрии, а затем к крупному фабрично-заводскому производству. Мануфактура не успела развиться и укорениться, как оказалась морально устаревшей в контексте общеисторического и технологического прогресса. Оборудование для создаваемых заводов, железных дорог и других сооружений поступало из центра страны. Появление и даже рост современных индустриальных комплексов не были системными, обусловленными действием внутренних факторов. Дополнительные трудности создавали существовавшие в Байкальском регионе различные экономические уклады.

Социально-экономическая реконструкция - индустриализация экономики, коллективизация сельского хозяйства, сопровождавшиеся культурной революцией, позволили продвинуться по пути фактического преодоления разрыва в уровне цивилизованности, сфоомировать социальную структуру в основном индустриального типа. Ее изменение предполагало соответствие потребностям и возможностям планового хозяйства. Главной силой социальных преобразований должен был стать рабочий класс, поэтому его доля в структуре общества увеличивалась наиболее высокими темпами. Так, к примеру, за 19261939 гг. численность рабочих в Бурятии увеличилась в 4 раза, с 22,7 тыс. $(4,6 \%)$ до 87,8 тыс. человек (36,3\%). В состав рабочего класса входили рабочие государственного, кооперативного и частного секторов. Большое внимание уделялось количественному росту рабочих государственной промышленности, т.к. они являлись основной опорой правящей партии. К концу второй пятилетки численность рабочих крупной государственной промышленности республики выросла в 14,7 раз (Балдано 2001: 92).

Ко времени образования Бурят-Монгольской АССР (1923) всего населения насчитывалось 482,1 тыс. человек, из них около половины составляли буряты. К 1926 г. все занятое население Бурятии делилось на следующие социальные группы: рабочие - 1,2\%, служащие - 0,5\%, крестьяне - 98,2\%, лица свободных профессий - 0,1\%. Индустриализация потребовала на промышленные стройки огромного количества рабочих рук. Для усиления притока рабочих из сельского хозяйства в индустриальные отрасли в июне 1931 г. было принято постановление ЦИК и СНК СССР «Об отходничестве». Этим постановлением для колхозников и единоличников, уходивших на работу в промышленность, строительство и транспорт, был установлен ряд льгот, что стимулировало перелив рабочих рук из аграрного сектора в промышленный. Количество рабочих в государственной промышленности возросло с 1928 по 1932 гг. в 2 раза, а общее число лиц, работавших по найму, в 1932 г. составило 41,6 тыс. против 10,7 тыс. чел. в 1930 г. (Балдано 2001: 143).

Одним из главных последствий социалистической индустриализацииурбанизации было абсолютное и относительное сокращение сельского населения и сельскохозяйственной занятости. За короткий срок произошел значительный перелив рабочей силы из сельского хозяйства в промышленность и иные сферы деятельности, в результате чего аграрно-традиционные структуры разрушались, а на их месте складывались новые социальные и профессиональные слои и группы, менялся их национальный состав, развивались индустриальные системы производства и потребления. В городах Байкальского региона в общем приросте город- 
ского населения почти 80\% составляли вчерашние сельские жители. К примеру, в Верхнеудинске/ Улан-Удэ, как и в других городах региона, численность населения имела тенденцию к резкому увеличению и составила в 1923 г. - 20,5 тыс. чел., в 1926 г. - 28,8 тыс. чел., 1939 - 125,7 тыс., 1959 г. - 174,3 тыс., 1970 г. - 253,6 тыс., в 1980 г. - 303,2 тыс., 1990 г. - 358,3 тыс., в 2002 г. - 367,4 тыс. чел. (Балдано 2011: 95). В 2017 г. численность улан-удэнцев составила 431922 чел. (Города... 2017).

Подобный рост в разные периоды был обусловлен различными причинами. В 1920-1930-е гг. в основном он объяснялся механическим движением мигрирующего в города населения, вовлекаемого в производство и вновь развертываемое строительство. Крупномасштабному росту численности горожан в 1960-1980-е гг. способствовали многие фракторы - социально-экономический, политический, демографрический, или, как часто говорят, «демографический взрыв», массовые миграции из деревень, осуществление правительством государственных программ индустриализации, строительство новых городов, поселков. В городах, по существу, произошла смена населения. Процесс «крестьянизации» города принял внушительные размеры и имел далеко идущие последствия. Волны сельской миграции буквально «затопили» города региона (как, впрочем, и города всей страны), определив основную коллизию урбанизации на многие десятилетия. Становление городской цивилизации с самого начала катастрофически отставало от роста городов, колоссального наплыва сельского населения в центры, которые не успевали это население скольконибудь серьезно «переварить». С таким наплывом вчерашних крестьян, их адаптацией к городской среде с иными правилами игры и новой системой ценностей справиться было очень сложно.

С начала 1930-х гг. в республике началось строительство крупных промышленных предприятий: паровозовагоноремонтного, мясоконсервного, механизированного стекольного, мельничного, лесопильного и кирпичного заводов, электростанции. С интенсивностью промышленного строительства резко возросла численность городского населения. Главной особенностью миграционных процессов стало перемещение в столицу республики г. Улан-Удэ - единственный город на территории Бурятии, обладавший ведущей ролью в социально-экономическом и культурном развитии республики. Еще более высокой интенсивностью отличалось перемещение в Иркутск - столицу Восточной Сибири, в том числе и из Бурятии.

Несомненно, миграция оказала самое ощутимое влияние на темпы развития городского хозяйства, на обеспеченность трудовыми ресурсами, на фрормирование населения, как в количественном, так и в качественном отношениях. Этот вопрос заслуживает особого внимания, поскольку с ним связана принципиальная оценка влияния миграционных процессов на формирование городской среды, тесно переплетающейся с понятием городского образа жизни. Демографрический аспект данной проблемы заключается в том, что изучение образа жизни предполагает учет движения населения, его структуры. При этом в качестве субъекта городского образа жизни можно рассматривать не только социально-классовые и социально-профессиональные группы, которые являются ведущими структурообразующими элементами, но и другие довольно многочисленные группы, которые различаются между собой по социальнодемографическим характеристикам. Именно мигранты представляют собой одну из таких групп, которая, находясь в процессе социальной адаптации, оказала прямое влияние на городской образ жизни. Удельный вес горожан - уланудэнцев - поднялся за период с 1931-1937 гг. с 10,4\% до 24,6\%. Ежегодно чис- 
ленность городского населения увеличивалась на 16,5\%. Только в 1935 г. в город прибыло 52,4 тыс. чел., а выбыло 14,2 тыс. чел. Удельный вес жителей села среди прибывших составлял 63\%. Механический прирост был равен 38,2 тыс. чел. (Переведенцев 1963: 48).

Тенденция постоянного изменения количественного состава горожан базировалась на решении социальной задачи вовлечения в народное хозяйство значительных резервов трудовых ресурсов, имевшихся в сельской местности. Это создавало условия для увеличения численности городского населения. Наряду с этим в периоды строительства крупных промышленных комплексов в Байкальском регионе определяющую роль в процессе увеличения числа горожан сыграла интенсивность перемещения достаточно крупных потоков переселенцев из европейской части страны. При этом доминирующим фрактором роста количественного состава городского населения оставался естественный прирост населения.

Численность населения г. Улан-Удэ в 1939 г. составила 125,7 тыс., а численность жителей республики - 545,8 тыс. Для сравнения: в 1926 г. - 28,9 тыс. чел. и 388,9 тыс. чел., соответственно (Стат. сб. 1967: 8). С изменениями роста численности горожан Бурятии менялся и национальный состав городского населения, подавляющим большинством которого были русские. Наряду с этим наблюдалось и увеличение числа бурят-горожан: в 1939 г. уровень урбанизованности бурят составил $9 \%$.

Особое внимание уделялось процессу вовлечения коренного населения в индустриальное производство. В 1926 г. в Бурятии среди рабочих фрабричнозаводской промышленности представители коренной национальности составляли лишь 1,33\%, к концу 1930-х гг. удельный вес рабочих-бурят на промышленных предприятиях составлял уже 8-10\%. Одной из причин подобных изменений стал отток значительного числа бурят из аграрного сектора в город, в основе которого лежала проводимая политика приобщения коренного населения к передовым видам индустриального и интеллектуального труда. Буряты вовлекались в промышленное производство тремя путями: вербовкой, отходничеством, организованным набором. Причем наиболее распространенным был последний источник. В аймаки выезжали представители строящихся и действующих предприятий для проведения лекций $о$ хозяйственнополитическом значении строительства предприятий. Подобные мероприятия давали положительный результат: в 1932 г. на строительство ПВРЗ из аймаков прибыло 3213 чел., из них - 2019 колхозников, в числе которых было 1354 бурята (Митупов 1958: 39).

Что касается интеллигенции, то официальная статистика выделяет категорию служащих, включая сюда собственно интеллигенцию, а также служащихнеспециалистов. В целом численность служащих за 1926-1939 гг. выросла в 2 раза, в результате осуществления культурной революции была сформирована национальная прослойка интеллигенции. К концу 1930-х гг. она большей частью была представлена учительскими кадрами. Так, в 1939 г. из 116,4 тыс. бурят (21,3\%), проживавших в республике, было: учителей - 1140 чел. (31,2\%), врачей - 23 (6,9\%), инженеров - 12 чел. (2,4\%). В целом по республике к 1939 г. в Бурятии возникли отряды производственной интеллигенции, составлявшие 36,5\% (6200 чел.), административной интеллигенции - 22,7\% (3860), педагогической - 19,9\% (3380 чел.), медицинской - 10,7\% (1830 чел.), культурнопросветительской - 7,1\% (1200 чел.), художественной - 2,3\% (350), научной 0,8\% (140 чел.) (Балдано 2011: 97). 
Основным источником формирования интеллигенции было выдвиженчество и подготовка кадров через систему средних и высших учебных заведений, как в республике, так и за ее пределами. Использование «дореволюционной» интеллигенции было ограничено из-за незначительной ее численности и классовой политики партии. Многие представители старой интеллигенции были обвинены в "буржуазном национализме, панмонголизме» и физически уничтожены в период массовых репрессий 1937-1938 гг.

В 1932 г. в Верхнеудинске было 14 техникумов, восемь рабфаков, где готовили учителей, транспортников, специалистов сельского хозяйства, медицинских и других, работников, в этом же году был открыт первый вуз в республике - агропедагогический институт. В итоге осуществление индустриализации и успехи культурной революции обеспечили стабильный рост интеллигенции именно в тех отраслях экономики и культурной жизни, где требовалась высокая квалификация, специальное образование.

В результате социально-экономических преобразований в республике в 1930-е гг. сложилась новая социальная структура: рабочий класс - 36,3\%, класс колхозного крестьянства - 42,4\%, кооперированных кустарей $-1,4 \%$, единоличники, некооперированные кустари - 1,6\%, интеллигенция - 7,3\%, служащиенеспециалисты - 11\% (Митупов 1986: 52). Социально-экономическая политика привела к полному вытеснению частного сектора, подчинению промышленности и сельского хозяйства государственному планированию и управлению.

В истории советского общества индустриализация и урбанизация выступают как неразрывный процесс. Индустриальное развитие происходило на основе централизованного планово-директивного, лимитно-распределительного механизма, директивного ценообразования. Соответственно, важной чертой советской урбанизации стало то, что она определялась директивно-плановым характером экономики. Причем, ведущей тенденцией было постепенное распространение планового начала из области собственно развития производства, отраслей экономики на все области развития городов, включая социальные, демографические, культурно-бытовые, градостроительные аспекты, но не как имеющие самостоятельное и тем более приоритетное значение, а как средство обеспечения роста производства.

При ограниченности ресурсов главным условием выполнения таких планов стала дешевизна промышленного и иного хозяйственного строительства. Она обеспечивалась своеобразной системой организации производства, включавшей низкий уровень жизни рабочих и своеобразную «городскую политику», сутью которой была минимизация расходов на человека в городе путем жесткой экономии на жилищно-коммунальном строительстве, социально-культурной сорере, городском транспорте и т.д. Острая нехватка жилья, недостаточный уровень жилищно-коммунального хозяйства в городах, еще более низкие стандарты обустройства населения в пригородных зонах агломераций, в малых городах и поселках городского типа вели к строительству домов с «коммуналками» вместо отдельных квартир, бараков, в которых люди жили десятилетиями. Практически во всех городах региона подобные бараки до сегодняшнего дня находятся на балансе ЖКХ. Надо признать, что, таким образом, пусть на самом низком уровне, проблема обеспеченности жильем все же была решена.

В связи с возраставшей потребностью экономики в рабочих руках проводилась политика максимального «освобождения» людей, особенно женщин, для работы в общественном производстве. Весь быт перестраивался на коллективистских началах. За теоретическими обоснованиями «социалистическо- 
го быта» лежала вполне экономическая подоплека: расходы на строительство «поселений при заводах» предполагалось определять, исходя из численности занятого на них населения. Вовлечение женщин в производство за счет «освобождения» от домашнего хозяйства вело к экономии средств в социальной сорере так же, как и «коллективизация» быта.

В начале 1930-х гг. сложился механизм городского развития, доживший до конца 1980-х гг. В его рамках градостроительство и архитектура превратились в «государственное дело», подлежащее централизованному нормированию и управлению. Строительство, опиралось на единые каноны функционализма, причем жилищное строительство ориентировалось на социальные задачи «обобществления социалистического быта». Из сферы частной и хозяйственной жизни и взаимоотношений многочисленных субъектов на местах они перешли в полностью централизованно регулируемую область, превратились в один из элементов механизма осуществления государственной власти и решения выдвигаемых партией задач. В результате города превратились в поселения при предприятиях, а градостроение полностью оказалось подчиненным производству, управляемому из центра.

Обычно город как носитель урбанизации характеризует концентрация разнообразия во всех сферах жизнедеятельности, в конечном счете - концентрация культуры, ее высших достижений. Но многие города региона сохраняли (и продолжают сохранять) исторически сложившийся «поселковый» характер, так как они формировались как сумма поселков при «своих» предприятиях. Все это резко снижало качество городской среды, консервировало поселковость, «слободизацию» городского расселения, и по сей день остается реальной преградой для развития подлинной урбанизации в современном понимании (Хренов 1999: 166).

Одной из особенностей советской модели урбанизации является маргинализация городского населения. Города региона отличались наличием маргинальных слоев населения с размытыми жизненными ориентирами, неадекватностью реакций, промежуточным, «пограничным» (между городскими и сельскими нормами) сознанием, провинциально-деревенским мышлением. Горизонтальные и вертикальные перемещения больших масс людей вели к маргинализации основных классов общества. Массовое перемещение сельских жителей в города не сопровождалось развертыванием социальной инфрраструктуры. Потеряв связь с деревенской жизнью, переселенцы не получили возможности полноценно включиться в городскую жизнь, возникла типично маргинальная - промежуточная, так называемая «барачная» субкультура. Обломки сельских традиций причудливо переплетались с наспех усвоенными «ценностями» городской цивилизации.

Физическая и социокультурная емкость городов оказалась недостаточной для того, чтобы переработать прибывавшие потоки «деревенских». Еще в конце 1970-х гг. известный российский исследователь Ж.А. Зайончковская утверждала, что «горожане в первом поколении неизбежно несут на себе печать маргинальности и промежуточности» (Зайончковская 1978: 15). Можно представить всю сложность вхождения в городскую жизнь вчерашних жителей сел и улусов, многие из которых не владели русским языком. Тяжесть физического труда, постоянный недостаток продовольствия, бытовая неустроенность усугубляли психологический дискомфорт, вызванный переменой места, образа жизни и характера труда. Отсюда - неудовлетворенность, огромная текучесть кадров, проявления девиации. Радикальный вариант деревенской культуры и ментальности - сельская молодежь. Именно от этой категории исходит отри- 
цание городской культуры. Свою чуждость ее нормам и условностям они переживают в весьма агрессивной, вызывающей форме или, во всяком случае, настойчиво подчеркивают ее. Это игнорирование городской культуры означает утверждение своей деревенской идентичности. Возродившиеся в 1990-е гг. землячества стали фрормой самоорганизации сельских мигрантов для лучшей адаптации в городе.

Городской житель часто был по своему сознанию, ментальности полугородским, жил сельскими представлениями, а отчасти и трудом, вне урбанистической культуры. Разумеется, по мере укоренения в городах бывших крестьян, крестьянских детей и внуков происходит их врастание в развивающуюся систему городских связей, маргинальность постепенно изживается. Однако скорость этого процесса неодинакова не только в различных социальных условиях, но и у отдельных индивидуумов.

Региональная специфика урбанизации определяется комплексом исторических, природно-климатических, геополитических и иных факторов. Байкальский регион отличается не только меньшей плотностью населения, в том числе и городского, но и меньшим удельным весом горожан в составе всех жителей. До 1917 г. на территории современной Бурятии существовало пять городов, только три из которых стали основой современных городских поселений: Верхнеудинск (Улан-Удэ), Троицкосавск (Кяхта) и Мысовск (Бабушкин). Отнесение населенного пункта к категории «город» чаще всего определялось административным актом присвоения статуса при игнорировании объективных параметров, необходимых городу. Особенно это относится к так называемым соцгородам - поселкам при производствах. Имея некоторые внешние признаки города, по социодемографическим, социокультурным и прочим признанным параметрам они таковыми не были и очень немногие из них начали формироваться как полноценные города. Многие города Байкальского региона как полифункциональные поселения, с экономической структурой, базирующейся на индустриальных отраслях производства, сформировались в начале 1930-х гг., когда были созданы те социальные образцы, по которым стали строиться и развиваться городские поселения, получившие свой социально-экономический статус. В регионе выделяются два города - Иркутск (главный город Иркутской области) и Улан-Удэ (столица Республики Бурятия), имеющие богатую историю. Однако второму трудно соперничать с первым, который представляет собой важнейший административный, экономический, транспортный, научный и культурный центр Восточной Сибири. Это Город в полном смысле этого слова.

Возвращаясь к Бурятии, нужно отметить, что ее богатые минеральносырьевые, лесные и водные ресурсы, не использовавшиеся в условиях царской России, уже в 1920-е гг. стали объектом усиленной разведки, изысканий, благодаря чему были открыты крупные запасы редких и ценных металлов, способствовавшие развитию отраслей добывающей промышленности. Открытие и разработка джидинских групп месторождений редких металлов (вольфрама и молибдена) послужили толчком к развитию горнодобывающей промышленности и нового промышленного района республики с центром в поселке Городок (г. Закаменск). Освоение Гусиноозерского угольного месторождения началось с 1935 г. Это способствовало созданию нового центра угольной промышленности БМАССР - поселка Шахты (г. Гусиноозерск).

Существенной особенностью городских поселений районов нового освоения со слабо развитым промышленным производством, небольшой плотностью населения и редкой сетью населенных пунктов, каким была Бурятия, яв- 
лялось то, что города играли специфическую роль как экономические, культурные центры окружающих территорий. В то же время многие из них вместо постепенного вызревания в очаги культуры превращались в большие общежития при предприятиях-гигантах. Это Шелехов, Усть-Илимск и Саянск в Иркутской области.

Несмотря на значительные изменения, уровень урбанизованности в Бурятии оставался невысоким. Поэтому особым направлением использования потенциала сложившегося расселения явилось преобразование сельских по статусу поселений в городские. В предвоенные годы была создана категория поселков городского типа - менее крупных, чем города, но обладавших некоторыми городскими чертами - Усть-Баргузин, Шахты (Гусиноозерск), Закаменск, Нижнеангарск. Хотя поселком городского типа в полном смысле этого слова их можно было назвать с большой натяжкой. В сущности, они представляли собой бараки, «засыпушки», выстроенные вокруг завода, шахты или рудника. На промышленные производственные ритмы накладывались ритмы сельскохозяйственные, что придавало поселению ту самую «поселковость», делая его селитебным приложением к фабрике или заводу. Также часто происходило и включение в состав города пригородных поселений. Довольно редко их земли использовались под новые застройки, чаще эти поселения становились составной частью города, не меняя строений и занятий обитателей, включая в городской ритм и городской ландшафт «сельские вкрапления». Таким образом, индустрия создавала новые районы города, лишенные полноценной городской среды.

Тем не менее, исходя из производственных и транспортных функций, в Бурятии сфрормировались городские поселения следующих типов: многофункциональный город Улан-Удэ; горнодобывающие центры Закаменск, Гусиноозерск; лесопромышленные центры Онохой, Выдрино; центры легкой и пищевой промышленности Кяхта, Чикой, Усть-Баргузин, Нижнеангарск; транспортные поселения Бабушкин, Танхой, Наушки. Городское население в 1939 г. составляло 30,7\% всего населения республики, тогда как в 1923 г. оно равнялось 9,2\%. В послевоенные годы получила развитие промышленность строительных материалов, быстро развивались легкая, лесная и лесообрабатывающая, угольная, пищевая промышленность, что привело к образованию новых промышленных поселков на территории республики (Каменск, Баянгол, Селендума, Холтосон).

К 1959 г. сеть городских поселений Бурятии включала пять городов и 13 поселков городского типа, где проживало 276,5 тыс. жителей, что составляло 41,1\% всего населения республики. Городские поселения стали основными пунктами концентрации промышленного производства и населения, административнохозяйственными и культурно-бытовыми центрами окружающих их территорий. К 1975 г. сеть городских поселений республики изменилась в количественном отношении за счет преобразования крупных сел в городские поселения.

В 1950-1960-е гг., когда формировался современный индустриальный облик Иркутской области, были построены такие города, как Шелехов, Железногорск, чуть раньше - Ангарск, Братск и др. Промышленные функции способствовали превращению их в многофукциональные города.

С конца 1970-х гг. в стране наблюдалась не совсем устойчивая тенденция снижения темпов роста численности горожан, некоторая стабилизация урбанизационных процессов и увеличение численности населения городов в результате естественного прироста. Примерно с этого времени в урбанизационных процессах наметились и стали действовать новые тенденции и 
явления. И среди них такие, как сближение условий труда и жизни в городе и деревне, внедрение в сельские районы элементов городской жизни, городской культуры и системы городских услуг, одним словом, «расползание» урбанизма, укрепление его воздействия и конкретных форм на горизонтальном (территориально-административном) и вертикальном (социально-профессиональном) уровнях. В СССР официально был провозглашен лозунг о стирании различий между умственным и фризическим трудом, между городом и деревней.

В отличие от развитых стран, где произошло выравнивание уровней развития - экономического, демографического, урбанизационного и т.д., в России, особенно в ее провинции, сохраняется диспропорция в темпах экономического и городского роста. Имеется и значительный разрыв в уровне урбанизации регионов страны. Отставание периферийных регионов по этому показателю, не говоря уже о степени урбанизированности общества, по всей видимости, сохранится еще не одно десятилетие.

Разрыв между урбанизацией и индустриализацией свидетельствует о незавершенности процесса промышленного развития и формирования городской системы, современного городского общества, что не создает всех необходимых предпосылок для более или менее равномерного и сбалансированного экономического и социокультурного развития. Незавершенность процесса урбанизации сказывается, прежде всего, на формировании городского общества и его социальной структуре, в которой наряду с современными слоями и группами сосуществует неотрадиционная сословность, клановость, кастовость, этнонациональный коммунализм и другие элементы и черты традиционности и архаики. Иными словами, традиционная, но не в чистом виде, сословность и современная этническая, конфессиональная, социальная и политическая фрагментарность все еще присутствует в городах региона, в том числе и в Улан-Удэ.

Еще одно существенное обстоятельство, заслуживающее внимания, это четко фриксируемая тенденция уплотнения городов, особенно Иркутска и УланУдэ, рост концентрации населения в них. В результате массовых миграций вчерашних крестьян и других социальных групп, утративших привычный образ жизни и занятий, здесь сосредоточена масса «избыточного» населения. И чтобы как-то прожить и выжить, особенно в условиях «лихих» 1990-х гг., большинство этих людей на собственный страх и риск занимались мелким или мельчайшим «бизнесом» в торговле, всевозможных видах личных и общественных услуг, а нередко нищенствовали и промышляли сомнительными занятиями воровством, наркоманией, проституцией, преступностью и прочими видами социальных отклонений.

В последние десятилетия в развитии городов Байкальского региона прибавились новые проблемы, связанные с модернизационными процессами, радикальной реконструкцией общества, с преодолением прошлого, сменой эпох и т.д. Расширился нематериальный сектор производства, включающий все виды торговли и коммерции, кредитно-финансовую систему, банки, страховые компании, государственно-общественные учреждения, систему услуг, массовые коммуникации, науку, просвещение, здравоохранение и т.д. Этому способствует ряд тенденций экономического, политического, социокультурного характера. Но говорить о завершении современной индустриализации-урбанизации в регионе, по всей видимости, еще рано. Кроме того, необходима новая городская политика в стране. 


\section{Список литературы}

1. Балдано М.Н. Индустриальное развитие Бурятии: достижения, издержки, уроки. - Улан-Удэ: ИПК ВСГАКИ, 2001. - 431 с.

2. Балдано М.Н. Урбанизационные процессы в Бурятии в 1930-е гг. // Вестник Бурятского научного центра Сибирского отделения Российской академии наук. - 2011. - № 2. - С. 93-100.

3. Бурятская АССР за 50 лет. Стат. сб. -Улан-Удэ, 1967. - 94 с.

4. Зайончковская Ж.А. Новоселы в городах. - М., 1978. - 164 с.

5. Митупов Б.М. Развитие промышленности и формирование рабочего класса в Бурятской АССР (1923-1937). - Улан-Удэ: Бурят. кн. изд-во, 1958. - 144 с.

6. Митупов К.Б.-М. Становление социалистической социальной структуры Бурятии (1938-1960 гг.). - Новосибирск: Наука, Сибирское отделение, 1986. - 133 с.

7. Переведенцев В.Н. Миграции населения и трудовые проблемы Сибири. - Новосибирск: Наука, Сибирское отделение, 1966. - 191 с.

8. Пивоваров Ю.Л. Урбанизация России в XX веке: идеалы и реальность // География мирового развития. Сборник науч. трудов. Сер. «география мирового развития». Под ред. Синцерова Л.М. - М., 2010. - C. 228-239.

9. Улан-Удэ. Города России // Города России. - URL: www.//xn----7sbiew6aadnema7p.xn-p1ai/sity_id.php?id=45\&sa=X\&sqi=2\&ved=0ahUKEwiM6seDr5TUAhWC2SwKHap8CpoQ9QEIDjAA

(Дата обращения: 15.05.2018).

10. Хренов Н.А. Субкультуры посада как субъекты урбанизационных процессов в России на рубеже XVII-XVIII вв. // Урбанизация в формировании социокультурного пространства. - М., 1999. C. $164-188$.

\section{Reference}

Baldano 2001 - Baldano, MN 2001, Industrial 'noe razvitie Buryatii: dostizheniya, izderzhki, uroki, IPK VSGAKI, Ulan-Ude', 431 s. (Baldano, MN 2001, The industrial development of the Buryatia Republic: achievements, costs, lessons, IPK VSGAKI, Ulan-Ude', 431 p). (in Rus).

Baldano 2011 - Baldano, MN 2011, Urbanizacionny`e processy v Buryatii v 1930-e gg, Vestnik Buryatskogo nauchnogo centra Sibirskogo otdeleniya Rossijskoj akademii nauk, № 2, P.93-100. (Baldano, MN 2011, Urbanization processes in Buryatia in the 1930s, Bulletin of Buryat scientific center of Siberian branch of the Russian Academy of Sciences, № 2, P.93-100). (in Rus).

Buryatskaya ASSR 1967 - Buryatskaya ASSR za 50 let: Stat. sb 1967, Ulan-Ude`, 94 s. (Buryat ASSR for 50 years: Stat.collection 1967, Ulan-Ude', 94 s). (in Rus).

Hrenov 1999 - Hrenov, NA 1999, Subkul tury` posada kak sub“ekty` urbanizacionny`x processov v Rossii na rubezhe XVII-XVIII vv, Urbanizaciya $v$ formirovanii sociokul turnogo prostranstva, Moscow, S. 164-188. (Hrenov, NA 1999, Subcultures of Posad as subjects of urbanization processes in Russia at the turn of XVII-XVIII centuries, Urbanization in the formation of socio-cultural space, Moscow, P. 164-188). (in Rus).

Mitupov 1958 - Mitupov, BM 1958, Razvitie promy`shlennosti i formirovanie rabochego klassa $v$ Buryatskoj ASSR (1923-1937), Buryat. kn. izd-vo, Ulan-Ude', 144 s. (Mitupov, BM 1958, development of industry and formation of the working class in the Buryat ASSR (1923-1937), Buryat. publishing house, Ulan-Ude', 144 p). (in Rus).

Mitupov 1986 - Mitupov, KB-M 1986, Stanovlenie socialisticheskoj social noj struktury 'Buryatii (19381960 gg.), Nauka, Sibirskoe otdelenie, Novosibirsk, 133 s. (Mitupov, KB-M 1986, Formation of the social structure of Buryatia (1938-1960), Nauka, Sibirskoe otdelenie, Novosibirsk, 133 p). (in Rus).

Perevedencev 1966 - Perevedencev, VN 1966, Migracii naseleniya i trudovy`e problemy`Sibiri, Nauka, Sibirskoe otdelenie, Novosibirsk, 191 s. (Perevedencev, VN 1966, Migration of population and labor problems of Siberia, Nauka, Sibirskoe otdelenie, Novosibirsk, 191 p). (in Rus).

Pivovarov 2010 - Pivovarov, YuL 2010, Urbanization of Russia in the twentieth century: ideals and reality, Geografiya mirovogo razvitiya. Sbornik nauch. trudov. Ser. "geografiya mirovogo razvitiya», Pod red. Sincerova LM, Moscow, S. 228-239. (Pivovarov, YuL 2010, Urbanizaciya Rossii v XX veke: idealy' i real'nost', The Geography of world development. Collection of scientific. labours'. Ser. "Geography of world development", Ed. Sincerova LM, Moscow, P. 228-239). (in Rus).

Ulan-Ude Nd - Ulan-Ude' Nd, Goroda Rossii retrivied 15 of May $2018<x n---7 s b i e w 6 a a d n e m a 7 p . x n--$ p1ai/sity_id.php?id=45\&sa=X\&sqi=2\&ved=0ahUKEwiM6seDr5TUAhWC2SwKHap8CpoQ9QEIDjAA>. (Ulan-Ude' $\mathrm{Nd}$, The cities of the Russiai retrivied 15 of May $2018<x n----7 s b i e w 6 a a d n e m a 7 p . x n--$ p1ai/sity_id.php?id=45\&sa=X\&sqi=2\&ved=0ahUKEwiM6seDr5TUAhWC2SwKHap8CpoQ9QEIDjAA>). (in Rus).

Zajonchkovskaya 1978 - Zajonchkovskaya, ZhA 1978, Novosely` v gorodah, Moscow, 164 s. (Zajonchkovskaya, ZhA 1978, New Settlers in the cities, Moscow, 164 p). (in Rus). 